\title{
Effect of sleep deprivation on hemorheological properties in alloxan induced diabetic rats
}

\author{
Okomafe N.E., Oluranti O.I*., Fasanmade A.A \\ Department of Physiology, College of Medicine, University of Ibadan, Ibadan, Oyo State, Nigeria.
}

Accepted April 8, 2017

\begin{abstract}
Diabetes mellitus with abnormal glucose concentration is associated with changes in hemorheological properties, endothelial function, and platelets hyperactivity. Disturbances may significantly be responsible for diabetes-related vascular complications. People with diabetes are also more likely to have sleep problem/poor sleep. This study therefore investigated the hemorheologic effect of sleep deprivation on alloxan induced diabetic rats. Sixteen healthy male Wistar rats were used for the study randomly divided into non diabetic non sleep deprived, diabetic non sleep deprived, non diabetic sleep deprived and diabetic sleep deprived groups with four animals each. The animals were paradoxically sleep deprived for fourteen days with a sleep deprivation chamber. The result revealed an increase in whole blood viscosity, hematocrit, fibrinogen concentration and relative plasma viscosity in diabetic rats. However, these blood rheological properties decline in sleep deprived diabetic rats. This suggests that diabetes increase hemorheological indices which could lead to vascular complications; while sleep deprivation in normal and diabetic state reduces the hemorheological indices. It is therefore possible that paradoxical sleep deprivation did not synergistically with diabetic condition to alter blood rheological properties but otherwise.
\end{abstract}

Keywords: Diabetes, paradoxical sleep deprivation, hemorheological properties, vascular complications

\section{Introduction}

Diabetes mellitus (DM) is a group of metabolic disorders characterized by a chronic hyperglycaemic condition resulting from defects in insulin secretion, insulin action or both (Ozougwu et al., 2013). Type 2 diabetes is caused by a combination of genetic factors related to impaired insulin secretion and insulin resistance and environmental factors such as obesity, overeating, lack of exercise, and stress, as well as aging. It is typically a multifactorial disease involving multiple genes and environmental factors to varying extents (Kaku, 2010). Hemorheological parameters in diabetes mellitus are often disturbed. These parameters include (but are not limited to) hematocrit, plasma proteins, erythrocyte

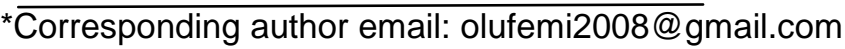

aggregation, and erythrocyte deformability. The abnormalities associated with each of these parameters have been shown to markedly increase both plasma and whole blood viscosity (WBV) (Cho et al., 2008). Studies have shown that vascular damage is one of the major characteristic of diabetes (Elishkevitz et al., 2002), which is accompanied by rheological abnormalities that can cause hyperviscosity syndrome (Moutzouri et al., 2008), that is, inadequate metabolic control associated with changing values of blood viscosity. Studies however have also shown that long term diabetes mellitus is associated with increased whole blood viscosity [Vigilance and Reid, 2005; Kaymaz et al., 2005) and decreased haematocrit (Thomas et al., 2006). It has also been suggested that these abnormalities in blood rheology, may play a causative role in the pathogenesis of diabetic vascular complications (Zhao et al., 2006). 
Sleep is a complex behavioral state spanning over onethird of the human life. Sleep deprivation consists either in a complete lack of sleep during a certain period of time or a shorter-than optimal sleep time which is commonly caused by contemporary lifestyle and workrelated factors (Orzeł-gryglewska, 2010). The prevalence of sleep disorders is increasing in modern societies, where constant exposure to artificial light and interactive activities, such as television and the internet, combine with social and economic pressures to shorten the time spent asleep (Tufik et al., 2009). Studies show that patients with diabetes experience more sleep problems than non-diabetic subjects (Nilsson et al., 2002; Happe et al., 2005). Indeed, sleep loss may adversely affect glucose tolerance and involve an increased risk of diabetes (Spiegel et al., 2005). Sleep disturbances are among the most prevalent impairments and may also have severe long-term effects upon health, including an increased risk of diabetes complications. Assessments of the effects of sleep loss on blood parameters associated with cardiovascular disease (CVD) is becoming a subject of considerable interest in view of the potential clinical relevance for the diagnosis and follow up of CVD patients (Andersen et al., 2004). Cardiovascular morbidity and mortality represent a main challenge in diabetic patients (UK Prospective Diabetic Study Group, 1998; Young et al., 1996). Considering chronic sleep deprivation as a debilitating factor, its effects on rheology properties of blood in diabetes has not been fully explored which necessitated this study in order to test the hypothesis that cardiovascular complications in diabetes might be mediated or aggravated by persistent sleep deprivation in patients.

\section{MATERIALS AND METHODS}

\section{Experimental design}

Sixteen healthy male wistar rats weighing between 180 $250 \mathrm{~g}$ were housed in cages under a $12 \mathrm{hr}$ light/dark cycle and provided with pelletized feed and water ad libitum. They were randomly assigned into four groups $(n=4)$ of non diabetic non sleep deprived, diabetic non sleep deprived, non diabetic sleep deprived and diabetic sleep deprived.

\section{Sleep deprivation procedure}

Animals were placed in a sleep deprivation chamber modified from (Suckecki and Tufik, 2000) where animals are allowed to move around freely. Animals to be sleep deprived were placed in the glass chamber to deprive them of sleep for $18 \mathrm{hrs}$ beginning at 16:00h per day for 14 days. After each $18 \mathrm{~h}$ sleep deprivation the rats were allowed to sleep for 6hrs (sleep window beginning at 10.00) (Venªncio et al., 2012). This sleep interval (10.00 to $14: 00 \mathrm{~h}$ ) was chosen because this is when paradoxical sleep attains its highest expression and slow wave sleep homeostatic pressure is generated (Machado et al., 2004).

\section{Diabetes Induction}

Diabetes was induced intraperitoneally using alloxan monohydrate powder at a dose of $100 \mathrm{mg} / \mathrm{kg}$ of body weight; 48hours after induction, the glucose level of the animals were monitored using a glucometer (Accu check) and rats with blood glucose level above $250 \mathrm{mg} / \mathrm{dl}$ were selected for the study (Huralikuppi, 1991).

\section{Blood collection}

$3 \mathrm{ml}$ of blood was collected into an EDTA bottle to measure whole blood viscosity, relative plasma viscosity and PCV while $2.25 \mathrm{ml}$ of blood was collected in $0.25 \mathrm{ml}$ of $3.8 \%$ sodium citrate to measure fibrinogen concentration. Plasma was collected by centrifugation at 2500 rpm for $15 \mathrm{mins}$.

\section{Hemorheological analysis}

Whole blood viscosity and relative plasma viscosity were estimated by the method described by Reid and Ugwu (1987) while Plasma Fibrinogen concentration was estimated by clot weight method of Ingram (1952). Haematocrit was measured using microhaematocrit reader.

\section{Statistical analysis}

Data were expressed as Mean \pm SEM. and analysed using one way analysis of variance (ANOVA) followed by post-hoc test, $p \leq 0.05$ was considered as significant.

\section{Results}

There were no significant changes in whole blood viscosity of the treated groups compared to the control. However, the values of DBSD and DBNSD were higher than the control (Figure 1).Figure 2 shows significant $(p<0.05)$ increase in relative plasma viscosity of DBNSD compared to NDBNSD. $a=P<0.05$. Also relative plasma viscosity of DBSD also increase compared to NDBNSD but not statistically significant $(P>0.05)$. Figure 3 shows 


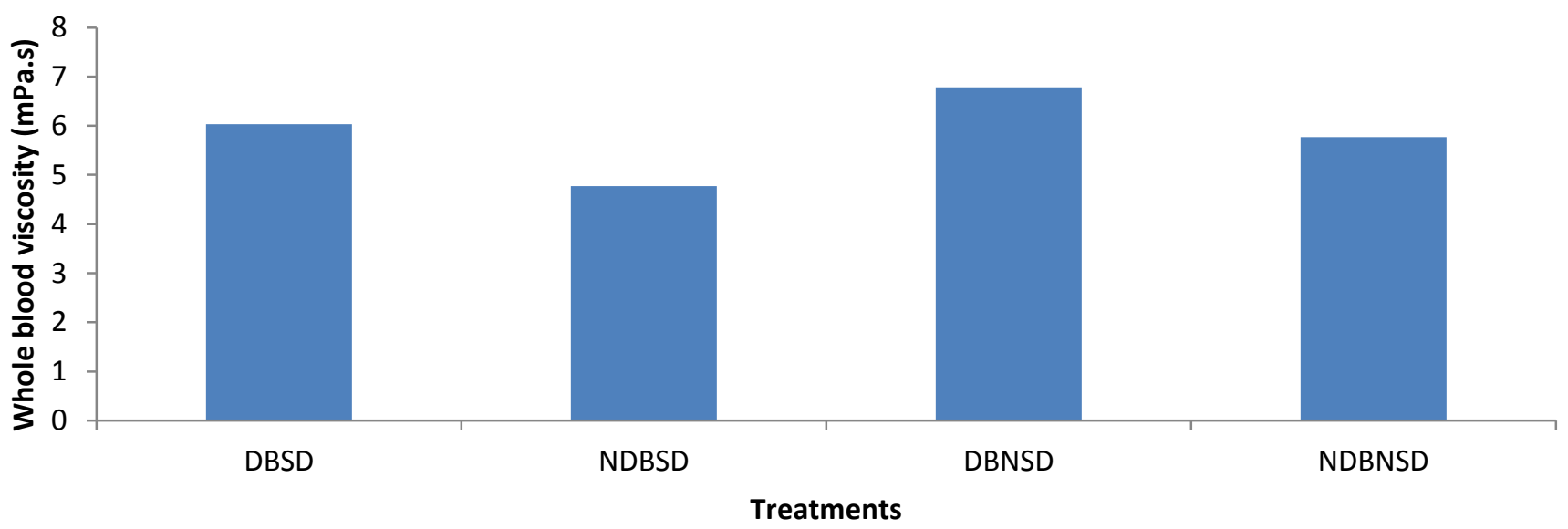

Figure 1: Variation in whole blood viscosity of the treated groups. NDBNSD (Control) = Non-Diabetic and non-sleep deprived (control); DBNSD = Diabetic non-sleep deprived (Diabetic control); NDBSD = Non - diabetic, sleep deprived; DBSD = Diabetic, sleep deprived.

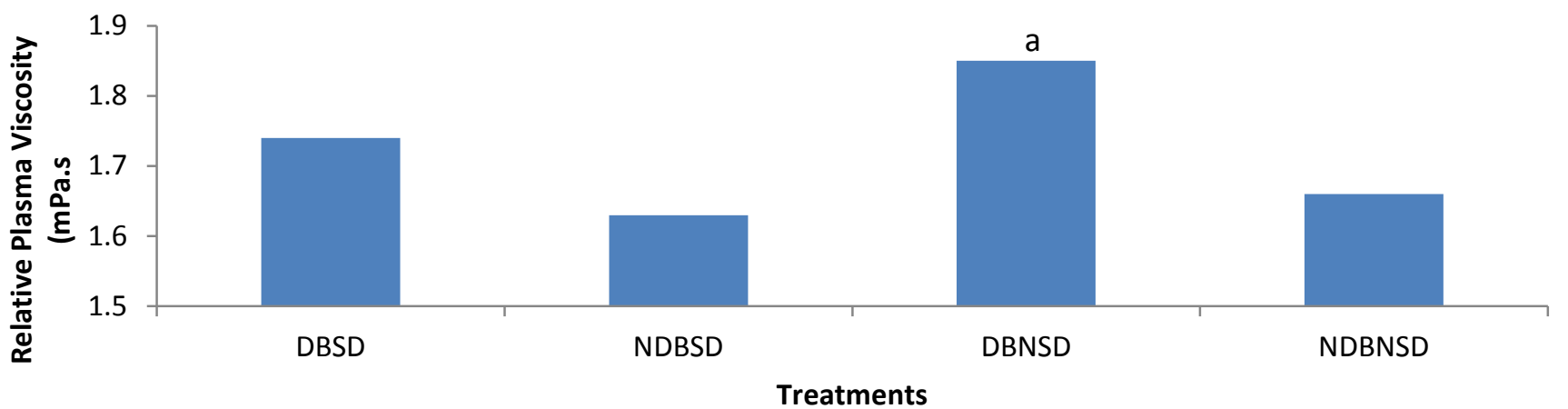

Figure 2: Relative plasma viscosity of all groups. NDBNSD (Control) = Non-Diabetic and non-sleep deprived (control);

DBNSD = Diabetic non-sleep deprived (Diabetic control); NDBSD = Non - diabetic, sleep deprived; DBSD = Diabetic, sleep deprived.

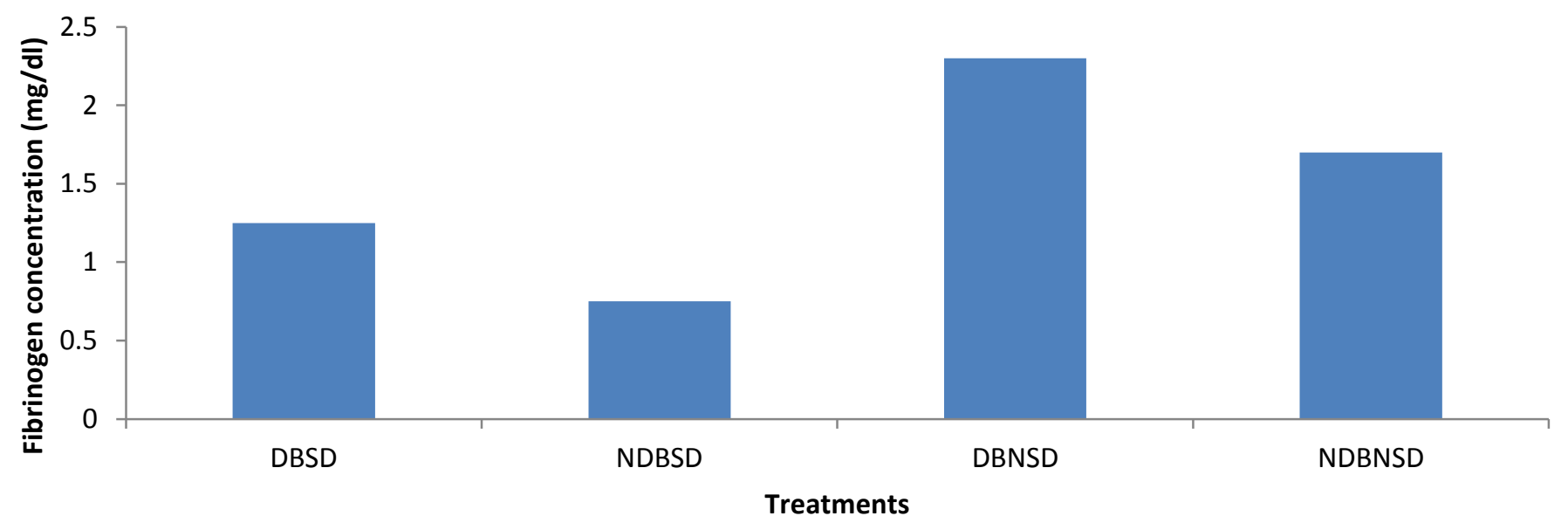

Figure 3: The graph shows the effect of sleep deprivation and diabetes on fibrinogen concentration. NDBNSD (Control) = Non-Diabetic and nonsleep deprived (control); DBNSD = Diabetic non-sleep deprived (Diabetic control); NDBSD = Non - diabetic, sleep deprived; DBSD = Diabetic, sleep deprived. 


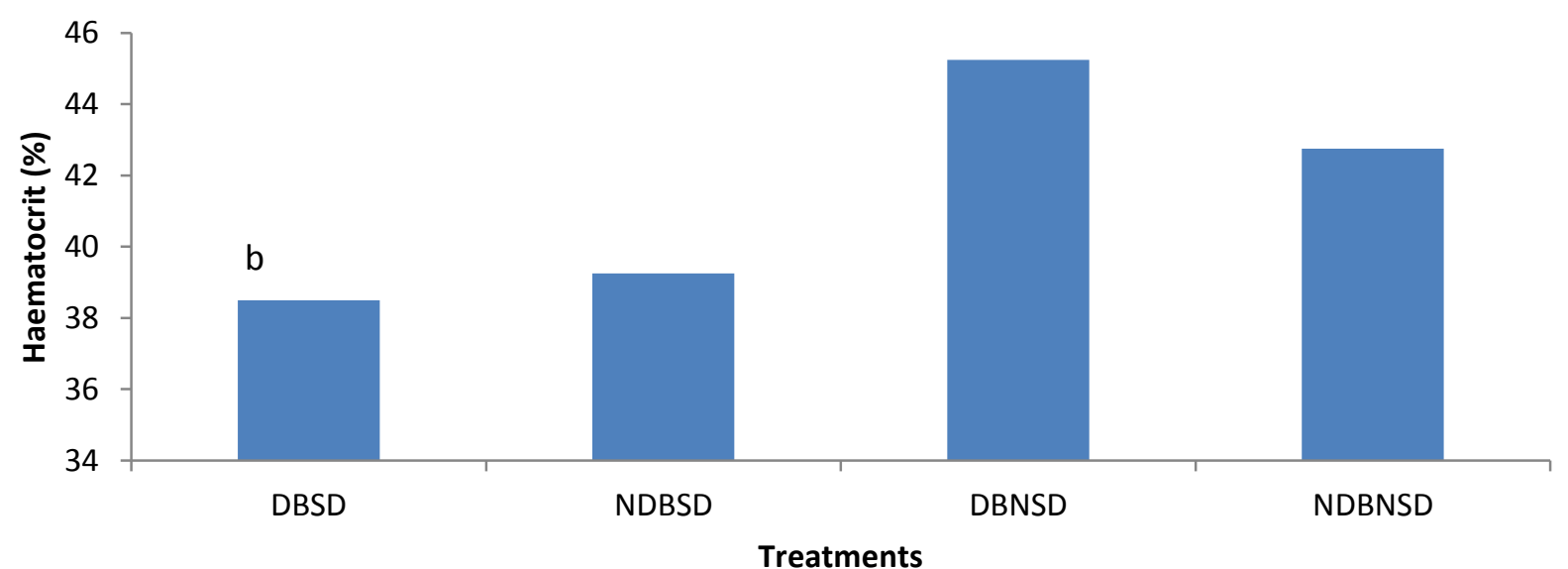

Figure 4: Hematocrit values of all groups. NDBNSD (Control) = Non-Diabetic and non-sleep deprived (control); DBNSD = Diabetic non-sleep deprived (Diabetic control); NDBSD = Non - diabetic, sleep deprived; DBSD = Diabetic, sleep deprived.

Table 1: Effect of sleep deprivation and diabetes mellitus on whole blood viscosity, relative plasma viscosity, fibrinogen concentration and hematocrit/PCV

\begin{tabular}{lcccc}
\hline Treatment & WBV (mPa.s) & RPV (mPa.s) & FIBC (mg/dl) & HCT (\%) \\
\hline DBSD & $6.03 \pm 0.27$ & $1.74 \pm 0.02$ & $1.25 \pm 0.24$ & $38.50 \pm 0.50^{\circ}$ \\
NDBSD & $4.77 \pm 0.12$ & $1.63 \pm 0.05$ & $0.75 \pm 0.36$ & $39.25 \pm 1.25$ \\
DBNSD & $6.78 \pm 0.39$ & $1.85 \pm 0.03^{\mathrm{a}}$ & $2.30 \pm 0.32$ & $45.25 \pm 2.25$ \\
NDBNSD & $5.77 \pm 0.64$ & $1.66 \pm 0.04$ & $1.70 \pm 0.59$ & $42.75 \pm 4.31$ \\
\hline
\end{tabular}

NDBNSD = Non-Diabetic and non-sleep deprived (control); DBNSD = Diabetic non-sleep deprived (Diabetic control); NDBSD = Non - diabetic, sleep deprived; DBSD = Diabetic, sleep deprived. $a=P<0.05$ when compared with NDBNSD, $b=P<0.05$ when compared with DBNSD.

the effect of sleep deprivation and diabetes on fibrinogen concentration. The diabetic non sleep deprived group (DBNSD) an elevated fibrinogen concentration compared to non diabetic non sleep deprived group though not statistically significant and also a decrease in fibrinogen concentration non diabetic sleep deprived group compared to non diabetic non sleep deprived group. There was a significant $(P<0.05)$ reduction in hematocrit value of diabetic sleep deprived group compared to diabetic non sleep deprived group as observed in this study(Figure 4).

\section{DISCUSSION}

Rheology can be an important tool in monitoring patients with diabetes mellitus because of the changes in blood viscosity in the pathogenesis of diabetes (Cho et al., 2008). In this study, whole blood viscosity (WBV), hematocrit (Hct) and fibrinogen concentration (FIBC) of diabetic rats were higher than the non diabetic rats but not statistically significant while the relative plasma viscosity (RPV) was significantly higher which is in conformity with some earlier works done in man (Reid and Memeh, 1988, Khan et al., 2005). Previous studies (Le Devehat et al., 2001; Cam et al., 2003; Vekasi et al., 2001) have also shown an altered and increase in these hemorheological parameters in diabetes patients. Blood viscosity and the development of diabetic angiopathy have been related to abnormal hematocrit, plasma viscosity, fibrinogen concentration and erythrocyte aggregation (Ziegler et al., 1994; Winberger and Baskurt, 2007). As the osmolarity of the blood increases due to increased sugar level, the capillary permeability increases, thus increasing hematocrit and subsequently the blood viscosity (Meiselman et al., 1967; Rizvi and Zaid, 2001).

The WBV, RPV, FIBC and Hct of non diabetic sleep deprived rats shows statistically insignificant $(P>0.05)$ reduction compared to non diabetic non sleep deprived rats indicating that sleep deprivation slightly reduced the blood rheological properties (Table 1). Sleep deprivation 
has been shown to be an independent risk factor for diabetes (Ayas et al., 2003) and has been associated with increased risk for hypertension (Ogawa et al., 2003). Although the exact pathophysiological mechanisms underlying the association between sleep deprivation and cardiovascular disease have not been defined, several potential explanations can be proposed. First, sleep deprivation in rats causes a decrease in the activity of anti-oxidative enzymes accompanied by markers of cell injury (Everson et al., 2005). Second, endothelin levels are elevated in sleepdeprived rats (Palma et al., 2002). Obstructive sleep apnea (OSA) is another primary sleep disorder associated with cardiovascular disease (Wolk et al., 2003; Shamsuzzaman et al., 2003). Sleep deprivation is one of the cardinal features of OSA. OSA has been linked to platelet activation (Bokinsky et al., 1995; Sanner et al., 2000), elevated fibrinogen levels (Wessendorf et al., 2000), increased whole blood viscosity, and decreased fibrinolytic activity (Rangemark et al., 1995). Furthermore, the Hct was significantly reduced in diabetic sleep deprived rats when compared to diabetic non sleep deprived rats while the fibrinogen concentration, relative plasma viscosity and whole blood viscosity also reduced insignificantly. This suggests the role of sleep deprivation in the reduction of blood viscosity in diabetic rats over a certain period which is in conformity with work done by Andersen et al., 2004 where they observed decrease in WBV of aged rats which at the time, they believed these change couldn't have been due to sleep restriction alone. Ajonijobe et al., 2016 also reported that sleep deprivation decreases red blood cell count and packed cell volume which could be due to suppression of erythropoiesis. The reduced hematocrit may be due in part to stress induced vitamin $D$ deficiency which is associated with sleep disorders (McCarty et al., 2014). This is possible because hypovitaminosis $D$ has been reported to induce hypophosphatemia which contributes to the severity of haemolysis (Mishra et al., 2015).Sleep deprivation lowers hemorheological indices in normal and diabetic rats while diabetes elevates hemorheological indices as this study has shown. We therefore conclude that diabetes alters whole blood viscosity, hematocrit, relative plasma viscosity and fibrinogen concentration which could eventually lead to vascular complications. Meanwhile, Sleep deprivation does not aggravate the hemorheological indices in diabetic state.

\section{REFRENCES}

Ajonijebu DC, Olayanju AO, Eduviere AT, Adewumi FA, Atodo KU, Akinsanya BT, Oresile AO, Musa A, Abboussi O, Sanya $\mathrm{JO}(2016)$. Effects of calcitriol supplementation on the hematological parameters of sleep deprived wistar rats. Int J Health Sci Res.; 6(3):127-134.
Andersen ML., Martins PJF, Almeida VD, Santos RF, Bignitto M, Tufik $S$ (2004). Effect of paradoxical sleep deprivation on blood parameters associated with cardiovascular risks in aged rats. Exp. Geront.; 39: 817-824

Ayas NT, White DP, Al-Delaimy WK, Manson JE, Stampfer MJ, Speizer FE, Patel S, Hu FB (2003). A prospective study of selfreported sleep duration and incident diabetes in women. Diabetes Care; 26:380-4.

Bokinsky G, Miller M, Ault K, Husband P, Mitchell J (1995). Spontaneous platelet activation and aggregation during obstructive sleep apnea and its response to therapy with nasal continuous positive airway pressure. A preliminary investigation. Chest; 108: 625-30.

Cam H, Püşüroğlu K, Aydin A, Ercan M. (2003) Effects of hemorheological factors on the development of hypertension in diabetic children. J Trop Pediatr; 49(3): 164-167.

Cho, Y. I., Mooney, M. P, Cho, D. J (2008). Hemorheological disorders in diabetes mellitus. J. Diabetes Sci. Technol.; 2: 11301138.

Elishkevitz K, Fusman R, Koffler M, Rotstein R. (2002) "Rheological determinants of red blood cell aggregation in diabetic patients in relation to their metabolic control," Diabetic Medicine; 19 (2): 152 156.

Everson CA, Laatsch CD, Hogg N (2005) Antioxidant defense responses to sleep loss and sleep recovery. Am J Physiol Regul Integr Comp Physiol; 288:R374-383.

Happe S, Treptau N, Ziegler R, Harms E (2005). Restless legs syndrome and sleep problems in children and adolescents with insulin-dependent diabetes mellitus type 1. Neuropediatrics; 36: 98103.

Huralikuppi JC. (1991).Antidiabetic effect of Nelumbo nucifera extract: Part 2. Phytother Res; 5: 217-223

Ingram GIC (1952) The determination of fibrinogen by the clot-weight method. Biochem J; 51: 583-585

Kaku K (2010). Pathophysiology of Type 2 Diabetes and Its Treatment Policy. JMAJ; 53(1): 41-46.

Kaymaz AA, Tarner S, Albeniz I, Cefle K, Palanduz S, Salmayenli N (2005). Alterations in rheological properties and erythrocyte membrane proteins in cats with diabetes mellitus. Clin Hemorheol Microcirc; 33: 81-88

Khan TM, Marwat MA, Khan P, Farman-ullah W, Amir R (2005). Plasma fibrinogen level in diabetics with complications - A prospective study. Gomal J Med Sci; 3(2): 48-50

Le Devehat C, Khodabandehlou T, Vimeux M. (2001) Impaired hemorheological properties in diabetic patients with lower limb arterial ischaemia. Clin Hemorheol Microcirc; 25(2): 43-48.

Machado RB, Hipolide DC, Benedito-Silva AA, Tufik S (2004). Sleep deprivation induced by the modified multiple platform technique: quantification of sleep loss and recovery. Brain Res; 1004: 45-51

McCarty DE, Chesson AL Jr, Jain SK, Marino AA (2014). The link between vitamin $\mathrm{D}$ metabolism and sleep medicine. Sleep medicine reviews; 18(4): 311-319.

Meiselman HJ, Merrill EW, Gilliland ER, Pelletier GA, Salzman EW (1967). Influence of plasma osmolarity on the rheology of human blood. J Appl Physiol.; 22(4): 772-781.

Mishra VA, Harbada R, Sharma A (2015). Vitamin B12 and vitamin D deficiencies: An unusual cause of fever, severe hemolytic anemia and thrombocytopenia. Journal of family medicine and primary care; $4(1): 145$.

Moutzouri AG, Athanassiou GA, D. Dimitropoulou, A. T. Skoutelis, and C. A. Gogos (2008) "Severe sepsis and diabetes mellitus have additive effects on red blood cell deformability," Journal of Infection; 57(2): 147-151.

Nilsson P, Rööst M, Engström G, Hedblad B, Janzon L, G Berglund (2002): Incidence of diabetes in middle age men is related to resisting heart rate and difficulties to fall asleep. Seventh international congress of behavioural Medicine, Helsinki, Finland (abstract).

Ogawa Y, Kanbayashi T, Saito Y, Takahashi Y, Kitajima T, Takahashi K, Hishikawa Y, Shimizu T (2003). Total sleep deprivation elevates 
blood pressure through arterial baroreflex resetting: a study with microneurographic technique. Sleep; 26:986-989.

Orzeł-gryglewska J (2010). Consequences of sleep deprivation. International Journal of Occupational Medicine and Environmental Health; 23(1): 95 - 114

Ozougwu JC, Obimba KC, Belonwu CD, Unakalamba CB (2013). The pathogenesis and pathophysiology of type 1 and type diabetes mellitus. J. Physiol. Pathophysiol; 4(4): 46-57

Palma BD, Gabriel A Jr, Bignotto M, Tufik S. (2002) Paradoxical sleep deprivation increases plasma endothelin levels. Braz J Med Biol Res; 35:75-9.

Rangemark C, Hedner JA, Carlson JT, Gleerup G, Winther K. (1995) Platelet function and fibrinolytic activity in hypertensive and normotensive sleep apnea patients. Sleep; 18:188-94.

Reid HL, Memeh CU (1988). Plasma and serum viscosity in diabetes mellitus. Nig J Physiol Sci; 4: 71-72

Reid HI, Ugwu AC (1987). A simple technique for rapid determination of plasma viscosity. Nig J Physiol Sci; 3: 45-48

Rizvi SI, Zaid MA (2001) Intracellular reduced glutathione content in normal and type 2 diabetic erythrocytes: effect of insulin and ()epicatechin J Physiol Pharmacol.;52(3):483-488

Sanner BM, Konermann M, Tepel M, Groetz J, Mummenhoff C, Zidek W (2000) Platelet function in patients with obstructive sleep apnoea syndrome. Eur Respir J; 16:648-52.

Shamsuzzaman AS, Gersh BJ, Somers VK (2003) Obstructive sleep apnea: implications for cardiac and vascular disease. JAMA; 290:1906-14.

Spiegel K, Knutson K, Leproult R, Tasali E, Van Cauter E (2005). Sleep loss: a novel risk factor for insulin resistance and type 2 diabetes. J Appl Physiol; 99: 2008-2019.

Suckecki D, Tufik S (2000) Social stability attenuates the stress in the modified multiple platform method for paradoxical sleep deprivation in the rat. Physiol Behav.; 68: 309-316

Thomas M, Tsalamandra C, Macisaac R, Jeruma G (2006). Functional erythropoetin deficiency in patients with Type 2 diabetes and anaemia. Diabetic Med; 23: 502-509.

Tufik S, Andersen ML, Bittencourt LRA, De mello MT. (2009) Paradoxical sleep deprivation: neurochemical, hormonal and behavioural alterations. Evidence from 30 years of research. Anais da Academia Brasileira de ciencias; 81(3): 521-538

UK Prospective Diabetic Study Group (1998). Tight blood pressure control and risk of macrovascular and microvascular complications in type 2 diabetics: UKPDS 38. Br Med J.; 317: 703-713

Vekasi J, Marton ZS, Kesmarky G, Cser A, Russai R, Horvath B. (2001) Hemorheological alterations in patients with diabetic retinopathy. Clin Hemorheol Microcirc; 24(1): 59-64.

Ven`ancio DP, Andersen ML., Vilamaior PSL, Santos FC, Zager A, Tufik S, Taboga SR, Demello MT (2012). Sleep deprivation alters rat ventral Prostate Morphology, Leading to Glandular Atrophy: A Microscopic Study Contrasted with the Hormonal Assays. J Med Biotech; 1-6
Vigilance JE, Reid HL (2005). Glycaemic control influences peripheral blood flow and haemorheological variables in patients with diabetes mellituus. Clin Hemorheol Microcirc; 33: 337-346

Wessendorf TE, Thilmann AF, Wang YM, Schreiber A, Konietzko $\mathrm{N}$, Teschler H (2000). Fibrinogen levels and obstructive sleep apnea in ischemic stroke. Am J Respir Crit Care Med.; 162:20392042.

Winberger U, Baskurt OK (2007). Comparative hemorheology. Handbook of hemorheology and hemodynamics O.K Baskurt et al. (eds) IOS Press; 267-285

Wolk R, Kara T, Somers VK (2003) Sleep-disordered breathing and cardiovascular disease. Circulation; 108:9-12.

Young MJ, Bennette JL, Liderth SA, Veves A, Boulton AJ, Douglas JT (1996). Rheological and microvascular parameters in diabetic peripheral neuropathy. Clin Sci (London); 96(3): 183-187

Zhao T, Guo J, Li H, Huang W, Xian X, Ross CJ, Hayden MR, Wen Z, Liu G (2006). Haemorheological abnormalities in lipoprotein lipase deficient mice with severe hypertriglyceridemia. Biochem Biophys Res Comm; 341: 1066-1071

Ziegler O, Guerci B, Muller S, Candiloros H, Méjean L, Donner M, Stoltz JF, Drouin P (1994). Increased erythrocyte aggregation in insulin-dependent diabetes mellitus and its relationship to plasma factors: a multivariate analysis. Metabolism; 43(9): 1182-1186. 